\title{
The application of modern media with an emphasis on satellite: media use and gratification approach
}

\author{
Mehrdad Matani $^{\mathbf{a}^{*}}$, Ramezan Hasanzadeh ${ }^{\mathrm{b}}$ and Ali Akbar Farhangi ${ }^{\mathrm{c}}$
}

${ }^{a}$ PhD student, Department of Media Management, Science and Research Branch, Islamic Azad University, Tehran, Iran

${ }^{b}$ Department of Psychology, Sari Branch, Islamic Azad University, Sari, Iran

${ }^{c}$ Department of Media Management, Islamic Azad University, Science and Research Branch, Tehran, Iran

\begin{tabular}{l}
\hline A R T I C L E I N F O \\
\hline Article history: \\
Received October 1, 2011 \\
Received in Revised form \\
November, 14, 2011 \\
Accepted 25 February 2012 \\
Available online \\
1 March 2012 \\
\hline Keywords: \\
Satellite channels \\
Use and gratification theory \\
TV application \\
Media content \\
Audiences
\end{tabular}
A B S T R A C T

\begin{abstract}
Satellite channels play an important role on building a connection among people with the same nationality who live in different parts of the world. The primary question is on how to serve various people with appropriate programs. In this paper, we present an empirical study among 310 audiences of satellite channels. The results show that the demographic characteristics of the audiences including age, gender, and education significantly influence the level of gratification with the satellite channels. From the cognitive perspective, they consider the satellite channels as tools for increasing their knowledge and from an emotional perspective; they consider these channels as enjoyable, entertaining and interesting.
\end{abstract}

\section{Introduction}

Due to fast advances, the lives of men have undergone several radical changes. One of these critical changes is the appearance of highly modern media. The media have changed so dramatically during the recent decades that one can hardly doubt their roles in human society. Presently, we live in a society, which seems highly media oriented and that the media atmosphere experiences highly radical changes. In the age of globalization, we quickly are aware of media services. This awareness leads us influence these changes on our lives. An important question may be raised with regard to the daily advancement of the media about the effects of these components on the human society and their audiences. That is, are we subjected to give an omnipotent role to the media and accept the perspectives of some experts who believe that the media not only transfer knowledge but also they tell us what knowledge is; not only determine our perspectives toward the world, but also tell us what kind of world exist (Holmes, 2005).

* Corresponding author. Tel. + 989126416019

E-mail addresses: mehrdadmatani@yahoo.com (M. Matani) 
On the other hand, some experts believe that the media do not play important role and the audiences accept the media according to their own social, familial, and situational context and can resist the communicative messages. These perspectives are highly important especially in terms of the newly developed media such as satellite and the internet. Satellite is one of the most eye-catching realizations of technological developments in media and communication. It is so vital that some experts have nominated the current era the satellite age. They believe that there is going to be a new version of society in which satellite governs. They believe that the satellite technology because of its expansion, attractiveness, and interesting invitation to the equality of cultures and behaviors dramatically affects human beings.

Nowadays, governmental supervision has decreased to some extent the access to satellite programs. The audience is the key element where the message is sent to and it is their interests, which determine the intake or rejection of the message. Communication planners, who imagine that if they aim at the audiences, they will gain success, actually make a big mistake. One of the key aspects of this mistake is that they consider the audiences as collective communicator; that is, one who is sufficiently motivated to use the media. Communicative planners, on the other hand, should look for the audiences who are willing to have effective communication; that is, willing to have a common strong desire to use media. Another model, which is important in studying the media audiences is to determine the tastes, and cultural patterns of the audiences. That is, they study the audiences in terms of the media and cultural patterns, which have shaped them, what social identity do they follow, and to what extent these identities are permanent. That is, it is impossible to communicate with the audiences without knowing their characteristics, effectively.

The active audience, nowadays, uses the media according to his/her needs, expectations and his/her own social and psychological backgrounds. That is, he/she selects the media and so the media influences him/her and this in its turn affects his/her future use of the media. Since the audiences select the media, they have to compete with one another in a way that they have to change their content, format and potential expectations so that adapt themselves to the weeds and expectations of the audience. According to the changes have been made in the perspectives associated with the media audience and the shift in experts' perspectives in terms of passive and active audience, knowing audience from different perspectives may be considered so critical with regard to technological boost and media competition. With regard to satellite televisions in general and Persian channels in particular, the audience is seldom asked to express his own idea. The research at hand tries to provide the audience with such an opportunity.

The general purposes of the study are to investigate the reasons of the audience for using the Persian satellite channels and to gain a better understanding of the audience. The specific purposes are to determine

- The relationship between emotional needs of the audience and their tendencies to use the Persian satellite channels,

- The relationship between cognitive needs of the audience and their tendencies to use the Persian satellite channels,

- The relationship between social needs of the audience and their tendencies to use the Persian satellite channels,

- The relationship between personal identity needs of the audience and their tendencies to use the Persian satellite channels,

- The relationship between the demographic characteristics of the audience and their media uses of the Persian satellite channels.

\subsection{Research questions}

- What are the most important needs of the audiences to use the Persian satellite channels? 
- Do the demographic characteristics of the audiences affect their media use of the Persian satellite channels?

\subsection{Research hypotheses}

- There is a relationship between emotional needs of the audience and their tendencies to use the Persian satellite channels.

- There is a relationship between cognitive needs of the audience and their tendencies to use the Persian satellite channels.

- There is a relationship between social needs of the audience and their tendencies to use the Persian satellite channels.

- There is a relationship between personal identity needs of the audience and their tendencies to use the Persian satellite channels.

- The search for media needs is different among different age groups.

- The search for media needs is different among different genders.

- The search for media needs is different among people with different educational background.

\subsection{Theoretical framework of the study}

The study at hand incorporates media use and gratification model as its theoretical framework. This is related to what people ask the media and do with their content. This model assumes that the audiences are actively engaged in finding the content, which provides them with utmost gratification. The degree of this gratification depends on the needs and interests of the audiences (Blumler \& Karz, 1974).

This was a reflection toward a communist view, which considered the audiences as passive and affected by the governing media. According to more recent view, people are active and can select and use the media (Ferguson \& Perse, 2000). The bases for this model are the gratification of the basic psychological and social needs. This is the route for media competition. The gratification may come from watching a soap opera or facing the social domains of the media. Bryant and Zillmann (1994) show the effect of personality types in selecting television programs; he believes that impatient audiences select exciting programs while stressed ones choose relaxing programs. A program may satisfy different needs among different people (Charndler, 1994). One selects the content of media for one's own gratification. The audience is not manipulated by the media; however, he/she uses the media to achieve his purpose (Baran \& Davis, 2000). This theory primarily believes that the audiences are prepared for media impacts; however in a more recent version this model is used to describe the audiences who are more sensitive to the audience message (Kim \& Rubin, 1997). The basics of this theory are as follow:

- The audience is active, it means that he has his own purpose and motivation

- The audience decides to use a special kind of media to satisfy his own needs and expectations

- The audience is influenced by his own psychological and social conditions

- The audience knows well why they are using media and their own purposes and motives

Among the available researches in terms of the media use and gratification, the research at hand incorporates the one presented by Blumler and Katz (1974). This model attempts to identify the motives of the audiences in terms of watching Persian satellite channels. According to this model, the influential variables are divided into two groups: one dealing with the needs and motives of using satellite channels and the second one the demographic variables such as gender, age and education.

\subsection{The concept of audience}

The word "audience" has several definitions and one can hardly find an agreed definition of it. The researchers of the field tend to consider the audience as one who voluntarily selects a medium. In 
some countries, the audience of television is defined as the one in a room with a television set. However, in some other countries, one is called audience when one considers himself a member of the audiences. The applied researches are dealing with the question that what the audiences do while watching televisions. Some experts believe that despite several studies have been conducted on television audiences, we do not have a deep understanding of them; since it is difficult to define, attract and keep the audiences (Jeffery, 1994).

There are many ways to classify the audiences of a TV. From a perspective, they can be categorized as a commune, products or agents. In a model, which considers audiences as a commune, a huge number of people considered to be temporally and spatially separated, act automatically, and do not know each other. The only common characteristic is to be the audiences of media. The question of this model is what media do these people use? In a model, which considers audiences and products, one thinks of people as creatures who act on the basis of media. This model reflects the power of media to negatively influence people. The main question of this model is what media do with people? In the last model, people are considered as ones who select the media freely. The main question is that what people do with the media? The advocates of this perspective believe that the reflections of audiences are determined by social and cultural factors. However, there are some studies, which do not completely lend themselves to these three models and considered to follow the variants of them. In a different classification, audiences are considered as active and passive.

Classification of the audiences of media into passive and active is very important in media studies. A theory considers audience as a passive receiver but the other one considers them as active receivers. Adams believes the tendency of people to turn on their televisions without considering the program is an example of passive receivers. The theory of active audience does not accept the idea that audiences decide to watch a program without knowing it. The theory believes that the action is based on gratification (Adams, 2000). The theory of use and gratification is based on active audience. The activity shows the volunteer and selective behavior of audience and refers to the motives of the audience to use media. In sum, one can say that different perspectives to audience are actually different assumptions about activity. Some studies do not accept the dichotomy and consider audience somewhere in between and put forward a mixed model such as limited influences perspective. Katz et al. (1974) believe that the use of media is shaped by similar expectations, which reflect what content predicts what audience (Lin, 1999). When discussing activity, some experts believe that active use of media as a moderating variable may affect their impacts (Kim \& Rubin, 1997). In this study, the following assumptions are made according to use and gratification perspective:

- $\quad$ The audiences of media have different goals and expectations while using them.

- $\quad$ The communicative behavior consists of the selection and use of media based on purpose and certain motives.

This approach tries to suggest a framework for determining when and how the consumers are active and what results are gained through their activity. It also tries to identify their motives and goals of using television programs as the signs of their needs and tendencies.

\subsubsection{Previous studies on media use and gratification}

Most studies done in Iran paid attention to television rather than its audiences; however, the studies done abroad mostly dedicated themselves to the audience rather than the television itself. In a study, Garamons discussed the role of motives and believed that the role of motives in the impacts of media is not always direct and the audiences' activity plays an important moderating role. Selective encounter is not considered as a facilitative factor of the activity, according to this study (Kim \& Rubin, 1997). Another study uses the media use and gratification framework to discover the patterns of news media among a college in Washington. According to Vincent and Basil (1997), the use of news media affects students' socialization. This confirms the theory of media use and gratification in that there is a correlation between gratification and the use of media. In a study developed by Cremer 
and Green (1999) according to the media use and gratification, the role of personality in individual preferences and the use of media violent content was studied. The study showed that there was a positive relationship between the tendency to excitement and the use of violent program and dangerous behaviors. The studies show that the gratification of the audience can be a result of being exposed to media, their content, and the social context. Another study on English and American audiences, showed that they watch television when there is nothing else to do and there is no tendency toward watching a special channel or program. Their involvement in television is relatively low and most people watch it for entertainment (Jeffery, 1994). The results of the study on watching cable television are in contrast to the findings of the Jeffery's research. It showed that the audiences are more active compared with those of ordinary television channels. Two third of audiences' time is spent watching unwanted programs and they mostly spend watching ordinary television channels (Jeffery, 1994).

\subsection{Uses and Gratifications Perspective}

The uses and gratifications theory is concerned with the way people use media in general, and television in particular. The objectives of uses and gratifications theory are (a) to explain how people use media to gratify their needs, (b) to understand motives for media behavior, and (c) to identify the functions or consequences that stem from needs, motives and behavior (Katz et al., 1974). One of the main assumptions of the uses and gratifications perspective is that media selection and use is purposive and motivated and that people take the initiative in selecting and using communication vehicles to satisfy felt needs and desires (Downing et al., 1990). Overall, the fact that consumers use media and specifically television purposefully in order to satisfy certain needs has long been supported by the uses and gratifications theory. The key concept of the uses and gratifications perspective is that the choices people make when consuming media are motivated by their desire to gratify a range of needs. This approach involves certain assumptions: (i) the audience is active; (ii) the audience makes motivated choices, based on previous experience with the media and (iii) media use is only one way amongst other to satisfy needs, which are experienced in everyday life. The needs the audience seeks to gratify while using media and in particular television, are: surveillance, personal identity, personal relationships and finally diversion. Surveillance suggests that the viewers inform themselves about something by using media. Surveillance for the viewers could be further defined as: finding out about events around them and the world in general so as to be aware of their surrounding environment, seeking advice for decision making as well out of curiosity or general interest, and finally learning in order to educate themselves or to feel secure by acquiring knowledge Personal identity refers to the "reinforcement of personal values", i.e. justification of behaviour.

The viewers may watch a program in order to compare themselves with the characters or real people shown on television, using them as positive or negative role models integration and social interaction means that audiences are watching the lifestyle and state of affairs of other people in order to "gain a sense of belonging". This 'sense of belonging' can be broken into two categories: First, viewers are able to place themselves in a specific social and economical context, either by comparison with different groups or by identification with their own. Second, viewers are able to discuss with other viewers on what they watched on television, and thus they could be able to place themselves in a community of viewers and to interact socially with others. Finally, diversion refers to using media either as a form of escapism from real life situations or as a means to cultural gratification and entertainment. On one hand, this means that viewers are bored or anxious and need a distraction to passively take their mind of things and relax, or "ritualized release" to actively divert themselves.(Martinez, 1992).

Based on the above evidences, it can be inferred that in relation to interactive TV applications, people will actively opt for and use the applications that best fulfill the needs that TV catered for. 
This approach has mainly contributed towards a better description: (i) of audience behavior; and (ii) of different kinds of content in terms of audience appeal notwithstanding a number of limitations of this approach have also been reported. First, it overemphasizes the "activity" of the audience, principally in the face of evidence showing where people have little selectivity and mostly rely on habitual and unthinking activities. Secondly, it has been argued that this approach is rather insensitive to media content itself largely ignoring the textual and cultural specifics of media content (MC Quail, 1998). Nonetheless, uses and gratification perspective becomes more valid as technology moves into an electronic information age. Advantages in media technology have allowed the audience to be more in control of the media, and since this approach is based on the concept of an active audience, it is especially appropriate for studying new communication technologies. The current Digital TV environment provides interactivity and therefore gives the audience the chance to be even more active and selective than before.

\section{Method}

The study at hand is a descriptive study, which surveys and gathers data through a questionnaire developed by the researchers. The population of this study is all the citizens of Qaemshahr who are 16 years old or above and watches Persian satellite channels. The unit of study in this research is individual, that is, the ones who have experienced watching Persian satellite channels. The conditions of membership in the population of the study is having the receiver equipments at home and watching it at home. This study has relied on nonrandomized sampling. The sample size is calculated to be 375 participants. After gathering the questionnaires, 310 questionnaires were found appropriate for further analysis. After calculating the reliability, which found to be .86 based on Cronbach's procedure and validity indices of the questionnaire, it was compared to those of the previous studies. The research is hence enjoys the face and content validity. The results were analyzed using SPSS using both descriptive and inferential procedures.

\section{Results}

The demographic analysis of the study shows that $49.7 \%$ of population is female and $50.3 \%$ is male. Moreover, most participants are under 22 years old and only $2.3 \%$ of them are older than 42 . In terms of education, $55.8 \%$ is graduate students and $13.9 \%$ is postgraduate students

\subsection{The analysis of first hypothesis}

There is a relationship between emotional needs of the audience and their tendencies to use the Persian satellite channels.

\section{Table 1}

The results of the analysis related to the first hypothesis

\begin{tabular}{lllllllll}
\hline Variable & participants & Calculated mean & Mean & Std Dev & t-student & Sig & $\alpha$ & p-valve \\
\hline $\begin{array}{l}\text { Satisfying } \\
\text { entertainment needs }\end{array}$ & 310 & 3.61 & 3 & .4165 & 25.84 & 309 & $\% 05$ & 0.000 \\
\hline
\end{tabular}

As it is shown in Table 1, the calculated mean (3.61) is significantly different from the theoretical mean, since the observed $t$ score in $\mathrm{p}<0.05$ is larger than the critical value of 1.64; we can judge that the audiences watch the channels to satisfy their entertainment needs.

\subsection{The analysis of second hypothesis}

There is a relationship between cognitive needs of the audience and their tendencies to use the Persian satellite channels.

As it is shown Table 2, there is a difference between the observed mean and the theoretical mean. The t-test shows that the difference is significant. The observed $t$ score 17.28 is larger than the critical 
value at $\mathrm{p}<0.05$ and it is safe to judge that the audience use the channels for finding cognitive information.

Table 2

The results of the analysis related to the second hypothesis

\begin{tabular}{lllllllll}
\hline variable & participants & Calculated mean & Mean & Std Dev & t-student & Sig & $\alpha$ & p-valve \\
\hline Cognitive needs & 310 & 3.77 & 3 & .7893 & 17.28 & 309 & $\% 05$ & 0.000 \\
\hline
\end{tabular}

\subsection{The analysis of third hypothesis}

There is a relationship between social needs of the audience and their tendencies to use the Persian satellite channels.

\section{Table 3}

The results of the analysis related to the third hypothesis

\begin{tabular}{lllllllll}
\hline variable & participants & Calculated mean & Mean & Std Dev & t-student & Sig & $\alpha$ & p- valve \\
\hline Social needs & 310 & 3.10 & 3 & .7441 & 2.44 & 309 & $\% 05$ & 0.015 \\
\hline
\end{tabular}

As it is shown in Table 3, the observed mean score 3.10 is significantly different from that of theoretical mean. The t-test shows the difference, as the observed $t$ score 2.44 is larger than the critical value. It can be concluded that the audience tend to watch the channels to satisfy their social needs.

\subsection{The analysis of fourth hypothesis}

There is a relationship between personal identity needs of the audience and their tendencies to use the Persian satellite channels.

\section{Table 4}

The results of the analysis related to the fourth hypothesis

\begin{tabular}{lllllllll}
\hline variable & participants & Calculated mean & Mean & Std Dev & t-student & Sig & $\alpha$ & p- valve \\
\hline $\begin{array}{l}\text { Gaining } \\
\text { personal } \\
\text { identity }\end{array}$ & 310 & 3.17 & 3 & .9225 & 3.29 & 309 & $\% 05$ & 0.001 \\
\hline
\end{tabular}

As it is reflected on the table above, the observed mean score 3.17 is significantly different from the theoretical mean. The t-test shows that the difference is statistically significant, since the observed value 3.29 is larger than the critical value 1.64 at $p<0.05$ level. It can be said that the audiences use the channels to satisfy their identical needs.

\subsection{The descriptive ranking of media use}

\section{Table 5}

Ranking the media use

\begin{tabular}{llll}
\hline & Factors & Mean & Ranks \\
\hline \multirow{3}{*}{ Main variables } & Cognitive information & 3.77 & 1 \\
& Entertainment needs & 3.61 & 2 \\
& Gaining identity & 3.17 & 3 \\
& Social needs & 3.1 & 4 \\
\hline
\end{tabular}

As it is shown in Table 5, the highest mean is related to the second question that is satisfying the cognitive information needs and the least one is related to the third question that is satisfying social needs.

\subsection{The analyses of moderating variables (demographic variables)}

The search for media needs is different among different genders. 


\section{Table 6}

Media use among different genders

\begin{tabular}{|c|c|c|c|c|c|c|}
\hline \multicolumn{2}{|l|}{ Gender } & \multirow{2}{*}{$\begin{array}{l}\text { Entertainment } \\
3.5555\end{array}$} & \multirow{2}{*}{$\begin{array}{l}\text { Satisfying cognitive } \\
\text { information } \\
4.1071\end{array}$} & \multirow{2}{*}{$\begin{array}{l}\begin{array}{l}\text { Social } \\
\text { needs }\end{array} \\
3.3416\end{array}$} & \multirow{2}{*}{$\begin{array}{l}\text { Gaining } \\
\text { identity } \\
3.4545\end{array}$} & \multirow{2}{*}{$\begin{array}{l}\text { Entertainment } \\
3.5555\end{array}$} \\
\hline \multirow{3}{*}{ Male } & mean & & & & & \\
\hline & participants & 154 & 154 & 154 & 154 & 154 \\
\hline & $\begin{array}{l}\text { Standard } \\
\text { deviation }\end{array}$ & .37020 & .64442 & .60711 & .78319 & .37020 \\
\hline \multirow{3}{*}{ Female } & mean & 3.6667 & 3.4466 & 2.8679 & 2.8942 & 3.6667 \\
\hline & participants & 156 & 156 & 156 & 156 & 156 \\
\hline & $\begin{array}{l}\text { Standard } \\
\text { deviation }\end{array}$ & .45217 & 78356. & .79328 & .96648 & .45217 \\
\hline
\end{tabular}

As it is shown in Table 6, the descriptive analysis shows that women use media more than men in terms of all needs except entertainment. In order to testify the difference t-test analysis is used.

\section{Table 7}

Differences between the genders in terms of media use

\begin{tabular}{lllllll}
\hline & & \multicolumn{2}{c}{$\begin{array}{l}\text { Levene's Test for } \\
\text { Equality of Variances }\end{array}$} & \multicolumn{2}{c}{ t-test for Equality of Means } \\
\hline & Equal variances & F & Sig. & t & df & p-value (2-tailed) \\
\hline Entertainment & assumed & 14.562 & .0000 & -2.367 & 308 & .019 \\
& not assumed & & & -2.370 & 297.839 & .018 \\
\hline Cognitive needs & assumed & 1.271 & .260 & 8.101 & 308 & .000 \\
& not assumed & & & 8.111 & $298 / 299$ & .000 \\
\hline Social needs & assumed & 14.303 & .000 & 5.902 & 308 & .000 \\
& not assumed & & & 5.912 & $290 / 196$ & .000 \\
\hline Gaining identity & assumed & 18.005 & .000 & 5.604 & 308 & .000 \\
& not assumed & & & 5.611 & $296 / 766$ & .000 \\
\hline
\end{tabular}

As it is shown in the table above, the differences are significant in $\mathrm{p}<0.05$ level. That is, the gender of the audiences affects the media use.

\subsection{The analysis of age variable}

The search for media needs is different among different age groups. Table 8 shows summary of our clustering.

\section{Table 8}

The mean of media use in different age groups

\begin{tabular}{lllll}
\hline Age & Entertainments & Cognitive needs & Social needs & identity \\
\hline Less than 22 & 3.4320 & 4.2009 & 3.4973 & 3.8177 \\
$23-26$ & 3.8036 & 3.6475 & 2.9908 & 2.9674 \\
$27-31$ & 3.6461 & 3.3095 & 2.7250 & 2.5655 \\
$32-36$ & 3.7205 & 3.5926 & 2.8370 & 2.9938 \\
$37-42$ & 3.4716 & 3.4271 & 2.6375 & 2.2188 \\
42 and above & 3.8442 & 3.4524 & 3.0286 & 2.6667 \\
\hline
\end{tabular}

As it is reflected in Table 9, the descriptive analyses of the date shows that the audience who are less than 22 years old have higher average media use in comparison with other age groups in order to testify the difference t-test is used.

As it is shown in Table 9, the differences are significant in $p<0.05$ level. It can be judged that the age affects media use. 
Table 9

Differences between the age groups in terms of media use

\begin{tabular}{llllllc}
\hline & & ss & df & Mean Square & F & p-value (2-tailed) \\
\hline entertainment & Between groups & 8.058 & 5 & 1.612 & 10.754 & 0.000 \\
& Inter groups & 45.559 & 304 & 0.150 & & \\
& sum & 53.617 & 309 & & & \\
\hline Cognitive needs & Between groups & 38.329 & 5 & 7.666 & 15.114 & 0.000 \\
& Inter groups & 154.189 & 304 & 0.507 & & \\
& sum & 192.519 & 309 & & & \\
\hline Social needs & Between groups & 32.715 & 5 & 6.543 & 14.374 & 0.000 \\
& Inter groups & 138.382 & 304 & 0.455 & & \\
& sum & 171.097 & 309 & & & \\
\hline identity & Between groups & 90.200 & 5 & 18.040 & 31.744 & 0.000 \\
& Inter groups & 172.761 & 304 & 0.568 & & \\
& sum & 262.961 & 309 & & & \\
\hline
\end{tabular}

\subsection{The analysis of education variable}

The search for media needs is different among different audiences with different educational background.

Table 10

Mean scores for media use among different groups of different educational background

\begin{tabular}{lllll}
\hline Educational level & entertainment & Cognitive needs & Social needs & identity \\
\hline College diploma & 3.3723 & 4.2004 & 3.4830 & 3.8298 \\
graduate & 3.7924 & 3.8362 & 3.1249 & 3.1098 \\
postgraduate & 3.4059 & 2.5969 & 2.1860 & 1.9884 \\
\hline
\end{tabular}

According to the above descriptive analysis, the audiences who have college diploma use media more in comparison with other groups. The graduate students mostly use media for entertainment. In order to testify the observed differences t-test is used.

Table 11

Variance analysis

\begin{tabular}{lllllll}
\hline & & ss & df & $\begin{array}{l}\text { Mean } \\
\text { Square }\end{array}$ & F & p-value (2-tailed) \\
\hline \multirow{3}{*}{ Entertainment } & Between groups & 12.857 & 2 & $6 / 429$ & $48 / 420$ & 0000. \\
& Intra group & 40.470 & 307 & $0 / 133$ & & \\
& sum & 53.617 & 309 & & & \\
\hline \multirow{3}{*}{ Cognitive information } & Between groups & 77.336 & 2 & $38 / 668$ & $103 / 063$ & 0000. \\
& Intra group & 115.183 & 307 & $0 / 375$ & & \\
& sum & 192.519 & 309 & & & \\
\hline \multirow{3}{*}{ Social needs } & Between groups & 49.809 & 2 & $24 / 905$ & $63 / 038$ & 0000. \\
& Intra group & 121.288 & 307 & $0 / 395$ & & 0000. \\
\hline \multirow{3}{*}{ Identity } & sum & 171.097 & 309 & & & \\
& Between groups & 101.583 & 2 & 50.791 & 96.624 & 0 \\
& Intra group & 161.379 & 307 &, 526 & & \\
\hline
\end{tabular}

As it is shown in Table 11, all the differences are significant at $\mathrm{p}<.05$ level. That is educational level affects media use. 


\section{Conclusion}

The main question of the research was to identify the main needs of the audiences of the Persian satellite channels. In order to answer the question media use and gratification model have been used. According to this model, the audiences try to satisfy their needs and affect the media through their activities. The results show that the audiences tend to use the satellite channels to satisfy their media needs and use it for different purposes. This study testifies the role of motives in media use. The study finds that the audiences tend use the media based on cognitive and learning needs, entertainment, gaining identity, and social needs. That is, the participants tend to approximately lend themselves to active audience model. The results show that the demographic variable affect the media use.

\section{Acknowledgements}

The author would like to thank the people that took part in this survey.

\section{References}

Adams, W. G. (2000). How people watch television as investigated using focus group techniques, Journal of Broadcasting and Electronic Media, 44, 78-93.

Baran, S., \& Davis, D. (2000). Mass communication theory: foundations, ferment and future. Belmont, CA: Wadsworth.

Blumler, J.G \& Katz, E. (1974). The uses of mass communication Newbury Pank, CA: sage.

Bryant, J., \& Zillmann, D. (1994). Entertainment as Media Effect. in: Media Effects: Advances in Theory and Research, eds. Bryant, Zillmann, Laurence Erlbaum Associates, Inc.,New Jersey.

Charndler D. (1994), why do people watch television? UWA.

Downing, J., Mohammadi, A., \& Sreberny, A. (1990). The nature of the audience. Questioning the media: A critical introduction. Newbury Park: Sage Publications.

Ferguson, D. \& Perse, E. (2000). The World Wide Web as a functional alternative to television. Journal of Broadcasting \& Electronic Media, 44 (2), 155-174.

Holmes, D. (2005). Communication Theory: Media, Technology, Society. London, SAGE.

Jeffrey, L. (1994). Rethinking audience for cultural industries: implications for Canadian research. Canadian Journal of Communications, 19(3/4), 241-268.

Kim, J., \& Rubin, A.M. (1997). The variable influence of audience activity on media affects. Communication Research, 24(2), 107-135.

Katz, E., Blumler, J.G. \& Gurevitch, M. (1974). Utilization of Mass Communication By The Individual, The Uses of mass communications: Current perspectives on gratifications research. Sage.

Kremer, M., \& Green, K. (1999). Predicting exposure to and uses of television violence. Journal of communication, 49(3), 24- 40.

Lin, C. (1999). Online-service adoption likelihood. Journal of Advertising Research, 39(2), 79-89.

Martinez, A. (1992). Scientific knowledge about television violence. Canadian radio- television and telecommunications commission.

MC Quail, D. (1994) Mass Communication Theory: An Introduction, 3rd ed. London: Sage publication

McQuail, D. (1987). Mass Communication Theory: An Introduction, Sage.

Palmgreen, P.H. (1984). Uses and gratifications: A theoretical perspective. In communication year book, $8,20-55$.

Phillip, T.K. (1982). The Application of Communication Theory and Research in the Legal Community.

Vincent, R. C., \& Basil, M. D. (1997). College students news gratifications, media use and current events knowledge. Journal of Broadcasting and Electronic Media, 41(3), 380-392

Phillip, T.K. (1982). The Application of Communication Theory and Research in the Legal Community.

Rahman H. A. (1998), Uses and Gratifications of Satellite TV in Egypt, MSc. Thesis, The American University in Cairo.

Vincent, R. C., \& Basil, M. D. (1997). College students news gratifications, media use and current events knowledge. Journal of Broadcasting and Electronic Media, 41(3), 380-392. 